\title{
The path from grey literature to Red Lists
}

\author{
N. Mrosovsky ${ }^{1}$, M. H. Godfrey ${ }^{2,3, *}$ \\ ${ }^{1}$ Department of Ecology and Evolutionary Biology, University of Toronto, 25 Harbord Street, M5S 3G5 Toronto, \\ Ontario, Canada \\ ${ }^{2}$ North Carolina Wildlife Resources Commission, 1507 Ann Street, Beaufort, North Carolina 28516, USA \\ ${ }^{3}$ Nicholas School of Environment and Earth Sciences, Duke University Marine Lab, 135 Marine Lab Road, Beaufort, \\ North Carolina 28516, USA
}

\begin{abstract}
This paper concerns the process by which Red List designations are decided and supported; it does not concern whether the past or present Red List categorizations are correct. We argue that, contrary to statements extolling the scientific and authoritative nature of the Red List, the reality for some species falls far short of these ideals. The prominent role played by the grey literature is an important factor in these problems. We use the case of the hawksbill turtle Eretmochelys imbricata as an example of the problems with relying on unavailable grey literature, but similar problems apply to various taxa classified in the Red List.
\end{abstract}

KEY WORDS: IUCN · Red List · Grey literature · Citations · Transparency Resale or republication not permitted without written consent of the publisher

\section{THE OFFICIAL NARRATIVE}

Dublin \& Smart (2006) refer to the Red Lists as the 'gold standard.' An IUCN (International Union for the Conservation of Nature) (2006) news release, just before the 2006 update of the Red List was made available on the web, says that these lists are 'widely recognized as the most authoritative assessment of the global status of plants and animals.' Such claims are taken up by the popular press. For instance, the Red List is called 'the most authoritative catalogue of species on the brink' (McIlroy 2007, p. 13). This view is also echoed in scientific journals. For example, one may read in 'Science' that the Red List is 'the most authoritative guide to today's extinction crisis' (Zimmer 2007, p. 892), and that it is used through much of the world 'as an objective and systematic tool' (Miller et al. 2006, p. 441).

The process of placing a species on the Red List should be objective, systematic, and transparent, in addition to having a strong scientific base and an authoritative nature. These goals require not only that the assessments be done by experts on that species, but also that the sources of information or opinion of the experts to be available and traceable. Otherwise what is meant to be authoritative becomes merely authoritarian. Transparent science gives way to secret science (Mrosovsky 1997).

For some species, including sea turtles, the reality of the listing process has fallen well short of the shining edifice presented in the official narrative. One of the main deficiencies concerns documentation.

\section{DOCUMENTATION}

The issue of availability of supporting documentation and Red List assessments is not new. When sea turtles were listed in 1996 (Baillie \& Groombridge 1996) under the 1994 IUCN system of categories and criteria (Version 2.3), there was no accompanying documentation in the published Red List, nor was any made available on request. Eventually, after various delays and a correspondence in the journal 'Nature' (Brackett 1997, Lapointe 1997, Meylan 1998, Mrosovsky 1997, 1998), the official position of the IUCN/SSC (Species Survival Commission) Marine Turtle Specialist Group (MTSG) on the status of the hawksbill turtle Eretmochelys imbricata was published 
in 1999 (Meylan \& Donnelly 1999). In 2000, the Red List category for 4 sea turtle species (hawksbills, greens Chelonia mydas, olive ridleys Lepidochelys olivacea, and flatbacks Natator depressus) was appealed under the IUCN appeals procedure. The appeal on the flatback listing was upheld by the Standards and Petitions Subcommittee (S\&PS) of the IUCN, but the appeals for the other 3 species, including those for the hawksbill, were unsuccessful (S\&PS 2001). However, the rulings included an important step toward promoting transparency and better documentation: the S\&PS said that 'all data used in a listing must either be referenced to a publication that is available in the public domain, or else be made available' (see Footnote 2 in S\&PS 2001). This same requirement was subsequently embedded into the Version 7.0 guidelines for the use of Red List categories and criteria (SPWG 2008).

Nevertheless, despite the establishment in 2001 of an olive ridley task force by the MTSG, by 2006 there was still no documentary support for the 'Endangered' status assigned to this species in 1996. So, that year, a second appeal for the olive ridley was submitted. The letter of appeal specifically stressed the absence of documentary support for the Endangered Red List status established in 1996. After receiving extensions beyond deadlines, the MTSG finally submitted a new and documented assessment for the olive ridley to the IUCN Red List program (Abreu-Grobois \& Plotkin 2007). This had references, but despite repeated requests and despite the IUCN standard requiring that these must be made available, the full complement of grey literature papers and communications was not made available. Nevertheless, the outcome of all this was that the status of the olive ridley was changed from 'Endangered' to 'Vulnerable', although because of the various delays this designation did not appear in the Red List itself until the 2008 update. At the end of the ruling, the IUCN Standards and Petitions Working Group (SPWG - the successor of the S\&PS) 'strongly encourages' those in the MTSG responsible for the assessment to make available all remaining sources of information (SPWG 2007).

Looking back on these events it is hard to escape the conclusion that producing scientifically supported, documented, and referenced listings for sea turtles has been promoted more by bringing these matters to the attention of a wider audience, and by appeals, than by IUCN pronouncements that the lists are authoritative, or by rulings about the availability of documents.

Turning from the olive ridley to Kemp's ridley Lepidochelys kempii, as of August 2008, i.e. $12 \mathrm{yr}$ after the listing was made, there is still no documentation for Kemp's ridley turtle in the Red List (www.iucnredlist.org).

\section{GREY LITERATURE AND CRITERION A}

Even with the species of sea turtles for which a documented and reasonably up-to-date assessment has been produced, major problems remain. The status assessments have relied mainly on Criterion A. This concerns the decline in numbers estimated to have occurred over the last $10 \mathrm{yr}$ or 3 generations, whichever is greater. Because sea turtles have long generation times, 3 generations can be many years ago. For example, for hawksbills, generation time is estimated to be 35 or $45 \mathrm{yr}$, depending on ocean basin (Mortimer \& Donnelly 2007). Therefore, 3 generations ago is either 105 or 135 yr before present, depending on ocean basin, which from 2005 comes out to 1900 or 1870. It may easily be imagined that information about numbers so long ago tends to come from grey literature.

Exactly what is considered grey is something that people may disagree about. In general, grey literature is described as 'any documentary material that is not commercially published and is typically composed of technical reports, working papers, business documents, and conference proceedings' (Mathews 2004, p. 125). We consider graduate theses to be part of grey literature, but others may not. Regardless, the major challenges associated with grey literature include uncertain availability and the lack of editorial control, raising questions about the authenticity and reliability of data contained within (Mathews 2004). Data contained in grey literature are potentially relevant to Red List assessments, but copies of grey literature must be made available so that they can be evaluated.

Seminoff \& Shanker (2008) reviewed 3 sea turtle Red List assessments produced since 2002, and found that 46 to $51 \%$ of all citations were from grey literature. Adding citations of personal communications or unpublished data to grey literature citations gives an astonishing 68 to $80 \%$ rate of citations that are not from published literature (Fig. 1). In accordance with the S\&PS directive, the MTSG co-chair's office established a website with copies of the grey literature cited in the hawksbill Red List assessment during the period when MTSG members were invited to review and comment on the draft. However, the website contained copies of only 59 out of 119 (49.6\%) grey items on 6 September 2007; that is, well after the comment period for MTSG members was over.

These numbers indicate that just under half (49.6\%) of the items of grey literature cited in this hawksbill assessment were made available. However, the situation is actually worse than this. By our count (and it is easy to miss items), there were also 17 personal communications and 46 'in litt.' citations quoted (some of them more than once) in the text but not in the refer- 


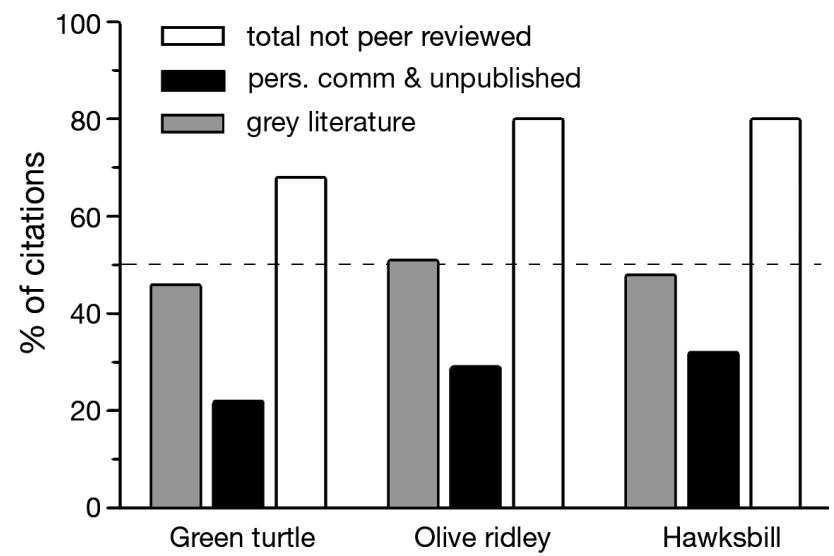

Fig. 1. Chelonia mydas, Lepidochelys olivacea, Eretmochelys imbricata. Relative occurrence of grey literature and personal communications/unpublished data citations in the 3 most recent Red List assessments for marine turtles (see www. iucn-mtsg.org/Red_List/). Data redrawn from Seminoff \& Shanker (2008)

ence list of the assessment. None of these are provided on the grey literature site. Therefore, the MTSG provided copies of only 59 out of $182(119+17+46)$ of the grey literature items cited, that is $32.4 \%$, or approximately $33 \%$, one-third.

Despite the fact that $>6$ yr ago the IUCN ruled that grey literature should be provided in the Red List process, this has not been achieved, at least not by the MTSG. The recent petition and subsequent reassessment of the status of the olive ridley turtle provided an opportunity to affirm this commitment and at the same time improve the scientific value of the documentary support. It would have been relatively easy for the SPWG to make the Red Listing contingent on or pending the provision of all the grey literature. Instead, in its final ruling on the olive ridley petition, the SPWG (2007) made some general but toothless exhortations that the remaining grey literature be made available. The same problem, but in a more acute form, has arisen with the assessment of the hawksbill turtle. In this case, there are many citations to grey literature, but only about one-third of that literature has been made available to the MTSG membership during their comment period. One-third only! That is a shockingly low figure. It calls into doubt the IUCN's commitment to having scientifically valid assessments, with traceable numbers.

The office of the MTSG co-chairs did put copies of some, but not all, grey literature from the hawksbill assessment onto its website. Whether the office was ever provided with all items we do not know. One way or another, after an encouraging start, the process fizzled out. None of the personal communications or in litt. citations were made available to group members who might have wished to consider those in their appraisals. Essential material relevant to describing or inferring numbers in 1900, or 1870 for some populations, was not available. What should be a verifiable, transparent process degenerates once again into secret science (Mrosovsky 1997).

We suspect that many gave opinions without bothering much about such details; some examples follow. When the Chair of the MTSG Assessment Steering Committee (of which one of us was a member at that time) circulated the draft assessment to that committee for comment, he also said 'I am sure most MTSG members would concur with your [the assessors'] status conclusion.' If MTSG members did so, they must have done this without an opportunity to appraise much of the grey literature supporting that view. This indicates an all round lack of concern about the draft being incomplete. Later on, the draft was circulated to the full MTSG membership. One commented: 'I have not personally examined that data, but believe that the assessors have no doubt followed official IUCN criteria carefully and done as scientific as possible an analysis, and that their conclusion is correct based on current criteria.' Another commented: 'The published reviewed literature is what we as professional scientists must rely upon when making these assessments.' He then went on to commend the assessors for their analysis 'with the best available published data.' If he had looked at the assessment, how could he have failed to notice that much of the supporting material was not reviewed, published data?

This is not directed against individuals, but is an exposition of events that collectively fall short of transparent presentation of the evidence on which the assessment was made, and lack of insistence that the basis for statements and numbers be available; it seems that some in the MTSG had little interest in such information. So, one may well ask, does anyone care about whether the evidence is available or not? Does the IUCN care despite having said grey literature should be available? If so, what is the Red List Program of the IUCN doing about this? After all, what is the point of asking a group of experts to review material without ensuring that they are able to access the details? Ironically, the leaders of the MTSG have written that 'Red List species assessments are perhaps the most publicly valuable contribution that the MTSG can make to the conservation of sea turtles and they must serve as examples of the group's professionalism and commitment' (Hutchinson et al. 2006, p. 21). Commitment: $>5$ yr from the establishment of the olive ridley task force, plus the imperatives of an appeal, to produce an assessment. Professionalism: failure to make all grey literature sources of information available. Even though the MTSG comprises some 280+ members, somehow these things do not get done. 
We provide 2 examples below from the hawksbill assessment (Mortimer \& Donnelly 2007) to show how the lack of access to grey literature can make it impossible to assess estimations of population declines.

\section{Case Study 1. Hawksbills in Brazil}

First, information from 3 sources is outlined below and then some additional comments are made.

(1) Marcovaldi \& Marcovaldi (1999) This reference was not cited in the hawksbill assessment. It relates that a comprehensive survey was made in 1980 and 1981, and it mentions that 'virtually nothing had been published about sea turtles in Brazil' (p. 35) and also at that time 'most urban agencies and universities in the northern region [conditions expected to be conducive to sea turtle nesting] had no information about sea turtles; indeed official sources assumed that there were no sea turtles at all in Brazil' (p. 35-36). So prior to 1980, this source says there is virtually no information about numbers, and none indicating large numbers historically. Statements by interviewees that populations were considerably larger in the past lack information on species or numbers and do not constitute a historical data set that lends itself to a quantitative analysis. (2) Marcovaldi et al. (2007) This paper states that, in northern Brazil (the primary nesting area for hawksbills in Brazil), there were between 1530 and 1820 nests $\mathrm{yr}^{-1}$. (3) The MTSG hawksbill assessment (Mortimer \& Donnelly 2007). Page 100 of this document gives the estimate for the present for Brazil as approximately 1750 nests, with the Marcovaldi et al. (2007) (Source 2 above) paper as the source. The past estimate (1901) is given as $>8750$ nests with Marcovaldi (pers. comm. 2006) as the source. Furthermore, the assessment also reports a population decline from 1901 to 1982, and a population increase from 1982 to 2005 (based on Marcovaldi's pers. comm. 2006 and Marcovldi et al. 2007).

The key question is how the past estimate of $>8750$ was obtained. From Marcovaldi \& Marcovaldi (1999) (Source 1 above), it is evident that there are virtually no historical data. Have these been unearthed since? If so, what exactly is the new information? It may be noted that in the hawksbill assessment, on page 103, Atlantic-Table 3 lists Brazil as an index site with historical data (Mortimer \& Donnelly 2007). For this assessment to be based on traceable numbers and be transparent, the historical information should be provided, as opposed to basing the assessment on personal communications that have not been made public. This is particularly desirable in this case, because there is a remarkable coincidence about the past estimate (8750) and the present one (1750): the decline from 1901 to 2005 comes out at exactly $80 \%$ (the threshold for one part of the criteria for the category of 'Critically Endangered')! In view of this, it would be reassuring to know there was independent evidence for the 8750 figure, and that this was not obtained simply by assuming there was an $80 \%$ decline from past to present and then calculating the past value that would result in such a decline. Another interpretation is that this process of attaching the branch on which one will be sitting, that is assuming a decline, extrapolating to the past, and then using the past figure in the calculations of the overall decline of the species, is-amazing though this may sound-actually sanctioned by the IUCN Guidelines for Assessing Taxa with Widely Distributed or Multiple Populations Against Criteria A (IUCN 2001) $)^{\mathbf{1}}$. In this case, if the decline in Brazil is inferred, it should be made clear. However, AtlanticTable 2 of the assessment gives no indication that this is so, as it should according to the guidelines just mentioned. This is especially relevant in this case as Source 1 above gives no grounds for inferring large populations historically.

Of course, it is possible that ultimately all may be in order with this example. However, the point is that one cannot tell without being able to see the relevant personal communications. If Red Listing is to be considered authoritative and based on the best existing science, it is not merely desirable, it is essential that all the grey literature be available. What conclusions should one draw if IUCN/SPWG does not attend to this?

\section{Case Study 2. Hawksbills in Panama}

In the recent hawksbill assessment (Mortimer \& Donnelly 2007), on page 102, Atlantic-Table 3 lists Chiriqui Beach in Panama as an index site with historical data. The historical data are given as 35 to 50 nesting females collected per mile per night at the peak of the nesting season (page 100, Atlantic-Table 2). The citations for the historical data are given as a published book (Carr 1956), a United States government report (Carr et al. 1982), and a peer-reviewed publication (Meylan \& Donnelly 1999). This would suggest that the historical data are based on 3 sources, only one of which is grey. However, upon inspection, one finds that the historical data reported (35 to 50 females harvested mile ${ }^{-1}$ night $^{-1}$ ) are mentioned neither in Carr (1956) nor in Carr et al. (1982). These data are taken from Meylan \& Donnelly (1999), where the citation for them is 'A. Meylan and P. Meylan, unpubl. data' (page 207). Thus, here is a case where the source of the historical data is unpublished and inaccessible, but because it is nested within a peer-reviewed publication cited in the Red List assessment, it gives the impression of being grounded in the scientific literature.

\footnotetext{
1This version was subsequently incorporated into the most recent version of the guidelines to using Red List categories and criteria (SPWG 2006)
} 
One might argue that the exact source or original location of the data is not important, rather the data themselves are important. We certainly agree. But how can one assess the quality of the data without being able to see the details of how and from where the data were derived? In the present example, we are told that these harvest values come from interviews in the 1980s in Panama with local 'veladores' (turtle hunters) who were asked about turtle numbers in the 1950s. How were the interviews conducted? Ideally, interviewers seeking factual information should make their questions as objective as possible, and should avoid asking leading questions that may induce respondents to give answers that they think the interviewers wish to hear (Bernard et al. 1984). It is highly possible that leading questions were used in the surveys in Panama, given that the sample survey questions detailed by Carr et al. (1982) include the following: 'Are sea turtles generally fewer nowadays than they used to be?' Again, had more detailed information on this source of data been provided, it would have been possible to evaluate (or perhaps eliminate concerns about) potential biases in the data.

To further point out the use of grey literature in the Chiriqui example, the data from 2003 to 2005 (see Atlantic-Table 2 on page 100 of Mortimer \& Donnelly 2007) come from a personal communication from Ordoñez and a presentation summary in a book of abstracts from a sea turtle symposium (Meylan et al. 2006). As details related to either of these reports were not provided, it is impossible to assess the quality of the data listed in the 'Present' column.

Altogether, the Chiriqui data provided in the hawksbill assessment are entirely based on grey literature and personal communications, none of which have been provided for review by the members of the MTSG. Again, it may be the case that nesting by hawksbills has precipitously declined in the last half century, but without access to the actual data and methods used to collect those data, verification is impossible.

\section{GREY LITERATURE AND OTHER SPECIES}

We have focused on marine turtles because of our familiarity and experience with this group. However, the use of grey literature and personal communications in the Red List assessments of other species is also pervasive. To illustrate this, we chose several different taxa with recently completed assessments on the Red List website, and then examined the associated references. We were surprised to find that between 11 and $83 \%$ (average of $40 \%$ ) of all citations consisted of grey literature or personal communications (Table 1).

Detailed consideration of the São Tomé short tail assessment is warranted. The assessment for this species on the IUCN Red List website gives coded numbers for the citations, and then gives a weblink to the summary references for all bird Red List assessments conducted by BirdLife International. However, it was necessary to find the Red List assessment on the BirdLife International website to get the author and year of each citation. In the case of the São Tomé short tail, we could not find full citations for 4 of the 6 references in the summary citation pages. It was only after further scrutiny of the individual assessment page that we discovered that personal communications are not included in the summary list of citations. None of these personal communications were elaborated upon, so it was impossible to assess the quality of the data or information that they provided. Regardless, we found it particularly difficult to link the reference codes in the text of the assessment with actual details of the citation in question. Therefore, housing all avian Red List assessments on the BirdLife International website has not led to greater transparency, at least in the case of the São Tomé short tail.

For the taxa listed in Table 1, information on how to obtain copies of the grey literature or personal communications were absent from the Red List website, with one exception. Three citations of grey literature for the

Table 1. Occurrence of grey literature (including personal communications) in selected Red List (RL) assessments. Citations were retrieved from the IUCN Red List website (www.redlist.org), except for Amaurocichla bocagei, for which citations were listed on the BirdLife International website (www.birdlife.org). Note that we did not score official IUCN Red List Program documents as grey literature. VU: vulnerable; EN: endangered

\begin{tabular}{|c|c|c|c|c|c|c|}
\hline Species & Common name & $\begin{array}{c}\mathrm{RL} \\
\text { status }\end{array}$ & $\begin{array}{c}\text { Year } \\
\text { assessed }\end{array}$ & $\begin{array}{l}\text { Total } \\
\text { references }\end{array}$ & $\begin{array}{l}\text { Total grey } \\
\text { literature } \\
\text { references }\end{array}$ & $\begin{array}{c}\text { Grey } \\
\text { literature } \\
\text { references }(\%)\end{array}$ \\
\hline Loxodonta africana & African elephant & VU & 2004 & 35 & 13 & 37 \\
\hline $\begin{array}{l}\text { Hippopotamus } \\
\text { amphibius }\end{array}$ & Common hippo & VU & 2006 & 21 & 10 & 48 \\
\hline Agabus clypealis & Northern European beetle & EN & 1996 & 2 & 1 & 50 \\
\hline Pseudagrion newtoni & Harlequin sprite damselfly & VU & 2007 & 9 & 1 & 11 \\
\hline Cephalorhynchus hectori & Hector's dolphin & EN & 2000 & 27 & 7 & 26 \\
\hline Uncia uncia & Snow leopard & EN & 2002 & 27 & 7 & 26 \\
\hline Amaurocichla bocagei & São Tomé short tail & VU & 2004 & 6 & 5 & 83 \\
\hline
\end{tabular}


hippopotamus assessment had hyperlinks associated with them; however, only 1 link had the relevant information in it; the other 2 links did not contain the relevant information cited in the assessment. Of the 7 assessments listed in Table 1, 2 were completed before 2001, when the S\&PS asserted the need to provide copies of grey literature (see above), so these should not be held to the same standards as assessments produced after 2001. However, the other 5 assessments were produced after 2001. This means that recent Red List assessments have not conformed to the standards of transparency that were instituted following the rulings in response to the first-ever official Red List petitions to 4 assessments under the 1994 criteria (S\&PS 2001). We encourage others with species-specific knowledge to evaluate the availability of supporting documentation for recent Red List assessments.

\section{MOVING FORWARD}

The Red List process has evolved over time, particularly with an emphasis on greater standardization and qualitative criteria (Mace \& Lande 1991, SPWG 2006). Transparency of the Red List process has also improved with the establishment of the Red List website that provides full accounts of species assessments. However, there is further room for improvement, particularly with respect to providing adequate documentation for the assessments. The widespread reliance on grey literature in the Red List process may be unavoidable, given the immediate relevancy of conservation research and the time lag between field data collection and publication in peer-reviewed journals. This does not change what is essential: to make the process of Red List assessments as transparent as possible and to make available all grey literature and personal communications. Improved transparency will lead to improved accountability (Lamoreux et al. 2003), and this, in turn, will help in producing the best and most realistic Red Lists possible.

Acknowledgements. We thank B. Godley, J. Seminoff, K. Shanker, and G. Webb for extended discussions on these topics.

\section{LITERATURE CITED}

Abreu-Grobois A, Plotkin P (2007) MTSG global assessment of olive ridley turtles for the IUCN Red List. Available at: www.iucn-mtsg.org/red_list/

Baillie J, Groombridge B (1996) 1996 IUCN Red List of Threatened Animals. IUCN, Gland

Bernard HR, Killworth P, Kronenfeld D, Sailer L (1984) The problem of informant accuracy: the validity of retrospective data. Annu Rev Anthropol 13:495-517
Brackett D (1997) No red alert over conservation Red Lists. Nature 389:904

Carr A (1956) The windward road. Alfred A. Knopf, New York

Carr A, Meylan A, Mortimer J, Bjorndal K, Carr T (1982) Surveys of sea turtle populations and habitats in the western Atlantic. NOAA Tech Memo NOAA-SEFSC-91. Available at: www.sefsc.noaa.gov/seaturtletechmemos.jsp

Dublin HT, Smart J (2006) One programme, one voice. Species 45:3-4. Available at: http://intranet.iucn.org/ webfiles/doc/SSC/SSCwebsite/Species_/species45_web. pdf

Hutchinson B, Mast R, Pilcher N (2006) Marine turtle (MTSG update). Species 46:20-22. Available at: http:// data.iucn.org/themes/ssc/publications/species/species_46_ hi-respdf.pdf

IUCN (International Union for Conservation of Nature) (2001) Guidelines for assessing taxa with widely distributed or multiple populations against Criterion A. IUCN Red List standards and petitions sub-committee, June 2001 (revised December 2001). Available at: www.iucn-mtsg. org/red_list/docs/Guidelines_widelydistspp.pdf

IUCN (International Union for Conservation of Nature) (2006) Release of the 2006 IUCN Red List of Threatened Species reveals ongoing decline of the status of plants and animals. IUCN News Release. Available at: www.nature serve.org/aboutUs/PressReleases/IUCN_Red_List_release. pdf

Lamoreux J, Akçakaya HR, Bennun L, Collar NJ and others (2003) Value of the IUCN Red List. Trends Ecol Evol 18: $214-215$

Lapointe E (1997) No red alert over conservation Red Lists. Nature 389:904

Mace GM, Lande R (1991) Assessing extinction threats: toward a reevaluation of IUCN threatened species categories. Conserv Biol 5:148-157

Marcovaldi MA, Marcovaldi GG (1999) Marine turtles of Brazil: the history and structure of Projeto TAMARIBAMA. Biol Conserv 91:35-41

- Marcovaldi MA, Lopez GG, Soares LS, Santos AJB, Bellini C, Barata PCR (2007) Fifteen years of hawksbill sea turtle (Eretmochelys imbricata) nesting in northern Brazil. Chelonian Conserv Biol 6:223-228

Mathews BS (2004) Gray literature: resources for locating unpublished research. Coll Res Libr 65:125-128

McIlroy A (2007) Vultures vanishing - even scavengers face extinction. Globe and Mail, 13 September 2007, Toronto, Canada, p A3. Available at: www.theglobeandmail.com/ servelet/story/LAC.20070913.SPECIES13/

Meylan A (1998) Hawksbill turtles still endangered. Nature 391:117

Meylan AB, Donnelly M (1999) Status justification for listing the hawksbill turtle (Eretmochelys imbricata) as critically endangered on the 1996 IUCN Red List of Threatened Animals. Chelonian Conserv Biol 3:200-224

Meylan A, Castillo I, Decastro N, Ordoñez C, Troëng S, Ruiz A, Meylan P (2006) Bastimentos Island National Marine Park and Playa Chiriqui: protected areas vital to the recovery of the hawksbill turtle (Eretmochelys imbricata) in Caribbean Panama. In: Frick $M$, Panagopoulou A, Rees AF, Williams K (eds) Book of abstracts from the 26th annual symposium on sea turtle biology and conservation. International Sea Turtle Society, Athens, p 145-146. Available at: www.seaturtle.org/ ists/proceedings.php

Miller RM, Rodríguez JP, Aniskowicz-Fowler T, Bambaradeniya $\mathrm{C}$ and others (2006) Extinction risk and conservation priorities. Science 313:441 
Mortimer JA, Donnelly M (2007) Marine Turtle Specialist Group 2007 IUCN Red List status assessment, hawksbill turtle (Eretmochelys imbricata). Available at: www.iucnmtsg.org/red_list/ei/

Mrosovsky N (1997) IUCN's credibility critically endangered. Nature 389:436

Mrosovsky N (1998) Plight of hawksbill turtles. Nature 392:646

S\&PS (Standards and Petitions Subcommittee) (2001) Red List petition results. Species 36:31-34. Available at: http:// intranet.iucn.org/webfiles/doc/SSC/SSCwebsite/species_/species36.pdf

Seminoff JA, Shanker K (2008) Marine turtles and IUCN Red Listing: a review of the process, the pitfalls, and novel

Editorial responsibility: David Roberts,

Kew, UK assessment approaches. J Exp Mar Biol Ecol 356:52-68

SPWG (Standards and Petitions Working Group) (2008) Guidelines for using the IUCN Red List categories and criteria, Version 7.0. Prepared by the Standards and Petitions Working Group of the IUCN SSC Biodiversity Assessments Sub-Committee, August 2008. Available at: http://intranet.iucn.org/webfiles/doc/SSC/RedList/ RedListGuidelines.pdf

SPWG (Standards and Petitions Working Group) (2007) Ruling of the IUCN Red List standards and petitions working group. Available at: www.iucnredlist.org/search/details. php/11534/all

Zimmer C (2007) Predicting oblivion: Are existing models up to the task? Science 317:892-893

Submitted: January 6, 2008; Accepted: September 11, 2008 Proofs received from author(s): November 5, 2008 